\title{
Characterization of Adipose-Derived Stem Cells Following Burn Injury
}

\author{
Anesh Prasai $^{1} \cdot$ Amina El Ayadi ${ }^{2,3} \cdot$ Randy C. Mifflin ${ }^{2,3} \cdot$ Michael D. Wetzel $^{1}$. \\ Clark R. Andersen ${ }^{2,3} \cdot$ Heinz Redl $^{4}$ • David N. Herndon ${ }^{2,3}$ • Celeste C. Finnerty ${ }^{2,3,5}$
}

Published online: 23 June 2017

(C) The Author(s) 2017. This article is an open access publication

\begin{abstract}
Severe burns induce a prolonged inflammatory response in subcutaneous adipose tissue that modulates signaling in adipose-derived stem cells (ASCs), which hold potential for healing burn wounds or generating skin substitutes. Using a $60 \%$ rat scald burn model, we conducted a series of experiments to determine which cells isolated from the adipose tissue produced inflammatory mediators and how these changes affect ASC fate and function. The stromal vascular fraction (SVF), adipocytes, and ASCs were isolated from adipose tissue at varying times up to 4 weeks postburn and from non-injured controls. Endpoints included inflammatory marker expression, expression of ASC-specific cell-surface markers, DNA damage, differentiation potential, and proliferation. Inflammatory marker expression was induced in adipocytes and the SVF at 24 and $48 \mathrm{~h}$ postburn; expression of inflammatory marker mRNA transcripts and protein returned to normal in the SVF isolated 1 week postburn. In enriched ASCs, burns did not alter cell-surface expression of stem cell markers, markers of inflammation, differentiation potential, or proliferative ability. These results suggest that adipocytes and
\end{abstract}

Celeste C. Finnerty

ccfinner@utmb.edu

1 Cell Biology Graduate Program, University of Texas Medical Branch, Galveston, TX, USA

2 Department of Surgery, University of Texas Medical Branch, Galveston, TX, USA

3 Shriners Hospitals for Children ${ }^{\circledR}$ — Galveston, Galveston, TX, USA

4 Ludwig Boltzmann Institute for Experimental and Clinical Traumatology, Vienna, Austria

5 Institute for Translational Sciences and Sealy Center for Molecular Medicine, University of Texas Medical Branch, 301 University Blvd., Galveston, TX 77555-1220, USA the SVF produce large quantities of inflammatory mediators, but that ASCs do not, after burns and that ASCs are unaffected by burn injury or culturing procedures.. They also suggest that cells isolated over $48 \mathrm{~h}$ after injury are best for cell culture or tissue engineering purposes.

Keywords Adipocytes · Adipose-derived stem cell · Adipose tissue $\cdot$ Burns $\cdot$ Inflammation $\cdot$ Stromal vascular fraction

\section{Introduction}

In 2013 alone, 35 million burn injuries were reported worldwide and resulted in approximately 2.9 million hospitalizations and 238,000 deaths [1,2]. In patients with large burns, wound coverage options are limited, mainly due to the lack of donor sites. New approaches are needed to cover massive burn wounds. Over the past decade, the discovery of adult mesenchymal stem cells in a plethora of tissues has enabled development of stem cell-based therapies for clinical use [2]. Stem cells isolated from adipose tissue (adipose-derived stem cells or ASCs) are similar to bone marrow-derived mesenchymal stem cells (MSCs) in that ASCs can differentiate into many cell types including chondrocytes, osteoblasts, adipocytes, cardiomyocytes, endothelial cells, epithelium, and neuronal cells. Furthermore, it is relatively easy to isolate up to 5000 ASCs from one gram of adipose tissue [3-5]. Aside from their ability to differentiate into a variety of cell types, ASCs also secrete an abundance of cytokines and growth factors, including interleukin (IL)-6, IL-7, IL-8, IL-11, IL-12, fibroblast growth factor, epidermal growth factor, keratinocyte growth factor, and macrophage colony-stimulating factor $[6,7]$. The production of these factors may account for the therapeutic effect of ASCs in wound healing [8,9], tissue regeneration [10], angiogenesis [11], and immunomodulation [9]. 
We and others have proposed that ASCs can be easily obtained from the subcutaneous adipose tissue that is discarded during debridement surgeries following a severe burn injury and that these ASCs can be used for wound healing or tissue regeneration [12-14]. Additional opportunities for ASC isolation are present during subsequent operations that massively burned patients must undergo and uncover other subcutaneous fat depots. Because coverage options for large burn wounds are limited, autologous ASCs could be applied to severely burned patients to facilitate wound closure; this could be accomplished either directly after harvest in the form of the stromal vascular fraction (SVF) or following manipulation of the enriched ASCs in culture to generate replacement grafts. We have recently shown that a severe burn injury induces a prolonged inflammatory response in subcutaneous adipose tissue isolated from unburned regions $[15,16]$. The effects of this inflammatory environment on ASCs are of concern, as inflammatory conditions such as diabetes have been shown to affect the basic properties of MSCs; when transplanted after myocardium infarction, MSCs from diabetic patients have a lower proliferative capacity and a weaker myocardial protective effect than MSCs from non-diabetic patients [17]. Studies on many different types of stem cells have revealed that the fate and function of a stem cell are controlled by factors in the microenvironment of the surrounding niche $[18,19]$.

Severe burn injury induces a systemic hypermetabolic and inflammatory response that results in elevation of stress hormones and inflammatory cytokines, which can last for several years. Long-term perturbations also occur in non-burned muscle, fat, and skin [20]. In adipose tissue, these responses can last for at least a year [20]. As a result, ASCs that reside at the burn site, those that migrate to the burn site through the circulatory system, and those residing in adipose depots far away from the burn injury are all exposed to altered levels of cytokines and hormones, as well as growth factors secreted in response to the burn injury. As the niche surrounding the stem cells defines the characteristics of these stem cells and can direct cell function and fate [19], we designed this study to determine which cells within the adipose tissue contributed toward the production of inflammatory mediators and whether ASCs are affected by the post-burn inflammatory environment. Using a $60 \%$ rat scald burn model, we analyzed inflammatory responses of adipocytes, the SVF (comprised of multiple cell types including ASCs, inflammatory cells, and preadipocytes), and enriched ASCs. Endpoints studied in the ASCs included differentiation potential, proliferation, cell surface cluster of differentiation and inflammatory marker expression, and DNA damage. We also determined whether the time of adipose collection postburn yields ASCs with differing properties, as much of our previous work shows a temporal pattern for burn-induced elevation of inflammatory mediators both systemically and within adipose tissue.

\section{Materials and Methods}

\section{Rat Model of Burn Injury}

All animal experiments adhered to the guidelines detailed in the NIH Guide for the Care and Use of Laboratory Animals. The study was reviewed and approved by the Institutional Animal Care and Use Committee of the University of Texas Medical Branch (Galveston, TX). Male Sprague-Dawley rats weighing $250 \mathrm{~g}$ were housed in an animal facility with a 12-h light and dark cycle for 1 week to acclimate prior to the initiation of the experiment. All animals received water and food ad libitum and were monitored for the entire study period. Eight animals were included in the control group, while 6 animals were included in each burn group. Prior to the burn injury, $0.05 \mathrm{mg} / \mathrm{kg}$ buprenorphine hydrochloride was administered as analgesia, followed by $40 \mathrm{mg} / \mathrm{kg}$ ketamine with $5 \mathrm{mg} / \mathrm{kg}$ xylazine (IP) as anesthesia. A $60 \%$ total body surface area scald burn was introduced in the manner previously described $[21,22]$. Resuscitation was accomplished by intraperitoneal injection of $60 \mathrm{~mL} / \mathrm{kg}$ Ringer's lactate solution. Buprenorphine hydrochloride was administered every $12 \mathrm{~h}$ to relieve discomfort. Rats were euthanized at $24 \mathrm{~h}$ or $48 \mathrm{~h}$ or at 1,2 , or 4 weeks following burn injury. Subcutaneous adipose tissue (0.9-3.0 g) was obtained from burned rats and sham-treated control rats for isolation of adipocytes, SVF, and/or ASCs at these time points.

\section{ASC Isolation}

Following its removal, adipose tissue was washed extensively with phosphate buffered saline (PBS) containing 5\% penicillin/streptomycin. The tissue was then minced and incubated with $0.075 \%$ collagenase Type IA at $37^{\circ} \mathrm{C}$ for 60 to $80 \mathrm{~min}$ with constant shaking. An equal volume of complete media (Dulbecco's Modified Eagle Medium, 10\% fetal bovine serum, and $2 \%$ antibacterial/antimycotic solution [10,000 IU/ $\mathrm{mL}$ penicillin, $10,000 \mu \mathrm{g} / \mathrm{mL}$ streptomycin, $25 \mu \mathrm{g} / \mathrm{mL}$ amphotericin, $8.5 \mathrm{~g} / \mathrm{L}$ sodium chloride]) was used to inactivate the collagenase. The solution was aspirated and centrifuged at $350 \mathrm{~g}$ for $5 \mathrm{~min}$ to separate the cells from the adipose tissue. The layer floating on the top was composed of mature adipocytes; these cells were removed and stored in RNA lysis buffer until analysis by real time polymerase chain reaction (PCR). The pellet at the bottom of the tube was the SVF, comprising endothelial cells, fibroblasts, ASCs, immune cells, and other cells. This SVF pellet was reconstituted with PBS and centrifuged at $350 \mathrm{~g}$ for $5 \mathrm{~min}$. This step was repeated 3 to 4 times until the supernatant became clear. The pellet was washed with water, and 10X PBS was added to lyse the red blood cells. After these steps, the pellet was resuspended in complete media and filtered through a $70-\mu \mathrm{m}$ cell strainer. The resulting mixture was divided into two aliquots. The first half was 
labeled SVF; these cells were preserved in RNA lysis buffer and stored for later analysis. The remaining aliquot was plated on two 100-cm dishes to isolate enriched ASCs. After an $18 \mathrm{~h}$ incubation, the media was aspirated to remove any unattached cells and debris, and complete media was added to the culture dishes. Following 30 additional hours of incubation, one plate of enriched ASCs was treated with RNA lysis buffer, and the lysate was stored for further analysis. The ASCs in the remaining plate were expanded in culture until the fourth passage was reached, and the cells were then used for further experimentation.

\section{Differentiation}

ASCs were grown for 4 weeks in complete media with the following components added to induce differentiation into each indicated cell type.

- Osteogenic cells: $0.1 \mu \mathrm{M}$ dexamethasone, $50 \mu \mathrm{M}$ ascorbate-2-phosphate, $10 \mathrm{mM} \beta$-glycerolphosphate, $0.1 \mu \mathrm{M}$ retinoic acid

- Adipogenic cells: $1 \mu \mathrm{M}$ dexamethasone, $10 \mu \mathrm{M}$ insulin, $0.5 \mathrm{mM}$ isobutyl-methylxanthine, $200 \mu \mathrm{M}$ indomethacin

- Chondrogenic cells: $6.25 \mu \mathrm{l} / \mathrm{mL}$ insulin, $10 \mathrm{ng} / \mathrm{mL}$ TGF- $\beta, 50 \mathrm{nM}$ ascorbate-2-phosphate, $2 \%$ fetal bovine serum

- Epithelial cells: $10 \mu \mathrm{M}$ all-trans retinoic acid

Cells were then harvested and fixed for histology or immunocytochemistry. Alternatively, RNA was isolated for real time PCR. Osteogenic cells were stained using alizarin red, adipogenic cells with oil-O-Red, and chondrogenic cells with alcian Blue. Epithelial cells were subjected to immunohistochemistry for CK-14. Nuclei were visualized with 4',6diamidino-2-phenylindole.

\section{Real-Time PCR}

Total RNA was isolated using the RNeasy mini kit (Qiagen, Chatsworth, CA) according to the manufacturer's instructions. RNA was quantified using the NanoDrop method (NanoDrop Technologies, Wilmington, DE); reverse transcription reactions were performed with $500 \mathrm{ng}$ of total RNA using the iScript cDNA synthesis kit (Bio-Rad, Laboratories, Hercules, CA). Real-time PCR was performed using SYBR green, while the Step One plus real time PCR system (ThermoFisher Scientific, Waltham, MA) was used for amplification and data collection. PCR conditions were as follows: $95^{\circ} \mathrm{C}$ for $10 \mathrm{~min}, 40$ cycles at $95{ }^{\circ} \mathrm{C}$ for $15 \mathrm{~s}$, and $55^{\circ} \mathrm{C}$ for $30 \mathrm{~s}$. The primer sequences are listed in Table 1 . The delta delta CT method was used to quantify gene expression, which was then normalized to expression of the internal housekeeping genes, glyceraldehyde 3-phosphate dehydrogenase (GAPDH) and cyclophilin A.

\section{Flow Cytometry}

Fourth passage ASCs were cultured in complete media until sub-confluent prior to flow cytometric analysis (Becton Dickinson FACSCanto cytometer, Franklin Lakes, NJ). Media was removed by washing the ASCs with PBS. The ASCs were then harvested with $0.25 \%$ trypsin/EDTA. Cell viability was assessed via propidium iodide staining. Determination of fluorescent cells, dead cells, debris, and background noise was made with FACS DIVA software (Becton Dickinson, Franklin Lakes, NJ). For extracellular staining, the cells were treated with a mixture of ice-cold $1 \%$ sodium azide for $30 \mathrm{~min}$, washed with PBS, and incubated with $3 \%$ bovine serum albumin (BSA) for $30 \mathrm{~min}$ on ice. Following a PBS wash, aliquots of ASCs were incubated in BSA with the following monoclonal antibodies for flow cytometry: CD73-Alexa 488 (BD Biosciences, San Jose, CA), CD90-Alexa 488 (BioLegend, San Diego, CA), CD11bAlexa 488 (BioLegend, San Diego, CA), CD34-PE (Santa Cruz Biotechnology, Dallas, TX), CD36-Alexa 488 (BioLegend, San Diego, CA), and CD29-PECy7 (BioLegend, San Diego, CA). For intracellular staining, cells were counted and fixed with $4 \%$ paraformaldehyde for $20 \mathrm{~min}$ at room temperature, washed three times with PBS, and lysed with $90 \%$ ice-cold methanol for $30 \mathrm{~min}$. The lysed cells were incubated in 3\% BSA for $30 \mathrm{~min}$ and treated with a monoclonal primary antibody to CD105-PE (Bioss Inc., Woburn, MA).

\section{Proliferation}

Cells were plated at a density of 5000 cells per well in xCELLigence ${ }^{\circledR}$ plates (ACEA Biosciences, San Diego, CA). Cellular attachment, spreading, and proliferation were monitored every $15 \mathrm{~min}$ using the real-time cell electronic sensing (RT-CES)® system (ACEA Biosciences, San Diego, CA), which measures cellular proliferation based on impedance. Cell-sensor impedance was expressed as an arbitrary unit called the Cell Index. Data were recorded for $55 \mathrm{~h}$ and then analyzed.

\section{Alkaline Single Cell Micro Gel Electrophoresis (Comet) Assay}

Comet assays were performed using the OxiSelect Comet Assay Slides according to the manufacturer's instructions (Cell Biolabs Inc., San Diego, CA). A cellular suspension in PBS $\left(1 \times 10^{5}\right.$ cells per $\left.\mathrm{mL}\right)$ was mixed 1:10 with molten lowmelting-point agarose at $37{ }^{\circ} \mathrm{C}$. Seventy-five microliters of this suspension were then placed within each well on the 
Table 1 Primers for CD marker characterization, differentiation, and inflammation

\begin{tabular}{|c|c|c|}
\hline Gene & Forward Primer & Reverse Primer \\
\hline Adiponectin & 5'-AATCCTGCCCAGTCATGAAG-3' & 5'-GTCCCCTTCCCCATACACTT-3' \\
\hline ALPB-1 & 5'-TAAGGGTGACCCAGGAGATG-3' & 5'-GGAACATTGGGGACAGTGAC-3' \\
\hline Osteonectin & 5'-CTGCCACTTCTTTGCGACCA-3' & 5'-CTCCAGGCGCTTCTCGTTCTC-3' \\
\hline Osteopontin & 5'-CTGGCAGTGGTTTGCCTTTGC C-3' & 5'-CGTCAGATTCATCCGAGTTCAC-3' \\
\hline ChM1 & 5'-GTGGTCCCACAAGTGAAGGT-3' & 5'-TCGACCTCCTTGGTAGCAGT-3' \\
\hline Collagen II & 5'-GAACAACCAGATCGAGAGCA-3' & 5'-CTCTCCAAACCAGATGTGCT-3' \\
\hline $\mathrm{CD} 11 \mathrm{~b} / \mathrm{c}$ & 5'-CTGGGAGATGTGAATGGAG-3' & 5'-ACTGATGCTGGCTACTGATG-3' \\
\hline CD73 & 5'-TCAAATCTGCCTCTGGAAAG-3' & 5'-ТTCСССТАСССАCТАССТТC-3' \\
\hline CD90 & 5'-AGCCAGATGCCTGAAAGAGA-3' & 5'- TGATAGAAGGGGGCTGAGAA-3' \\
\hline CD34 & 5'-TCTTGGCCAATAGCACAGAACT-3' & 5'-TGCAATCAGAGTCTTTCGGGAA-3' \\
\hline CD105 & 5'-CTGGAGCAGGGACGTTGT-3' & 5'-GCTCCACGCCTTTGACC-3' \\
\hline Cycophilin A & 5'-TATCTGCACTGCCAAGACTGAGTG-3' & 5'-CTTCTTGCTGGTCTTGCCATTCC-3' \\
\hline CK-10 & 5'-TGGTTCAATGAAAAGAGCAAGGA-3' & 5'-GGGATTGTTTCAAGGCCAGTT-3' \\
\hline CK-14 & 5'-GGCCTGCTGAGATCAAAGACTAC-3' & $\begin{array}{l}\text { 5'-CACTGTGGCTGTGAGAATCT } \\
\text { TGTT-3' }\end{array}$ \\
\hline IL-1ß & 5'-CACCTTCTTTTCCTTCATCTTTG-3' & 5'-GTCGTTGCTTGTCTCCTTGTA-3' \\
\hline IL-6 & 5'-CGAGCCCACCAGGAACGAAAGTC-3' & $\begin{array}{l}\text { 5'-CTGGCTGGAAGTCTCTTGCG } \\
\text { GAG-3' }\end{array}$ \\
\hline Caspase-1 & 5'-CACATTGAAGTGCCCAAGCT-3' & 5'-TCCAAGTCACAAGACCAGGC-3' \\
\hline MCP-1 & 5'-GTTGTTCACACTTGCTGCCT-3' & $\begin{array}{l}\text { 5'-CTCTGTCATACTGGTCACTT } \\
\text { CTAC-3' }\end{array}$ \\
\hline $\mathrm{NF}-\kappa \mathrm{B}$ & $\begin{array}{l}\text { 5'-GTGCAGAAAGAAGACATTGA } \\
\text { GGTG-3' }\end{array}$ & 5'-AGGCTAGGGTCAGCGTATGG-3' \\
\hline $\mathrm{TNF}-\alpha$ & 5'-TCAGCCTCTTCTCATTCCTGC-3' & 5'-TTGGTGGTTTGCTACGACGTG-3' \\
\hline
\end{tabular}

specially prepared microscope slide provided with the kit. Slides were incubated at $4{ }^{\circ} \mathrm{C}$ for $15 \mathrm{~min}$ to allow the agarose to solidify and then were placed in lysis buffer and incubated for $30 \mathrm{~min}$ at $4{ }^{\circ} \mathrm{C}$ in the dark. Denaturation was achieved by transferring the slides to a pre-chilled alkaline electrophoresis buffer (300 mM sodium hydroxide, $1.0 \mathrm{mM}$ EDTA) and incubating for $30 \mathrm{~min}$ at $4{ }^{\circ} \mathrm{C}$ in the dark. The slides were then transferred into a horizontal electrophoresis chamber (BioRad Inc., Hercules, CA) and subjected to electrophoresis at $1 \mathrm{~V} / \mathrm{cm}$ $(30 \mathrm{~V}, 300 \mathrm{~mA})$ for $15 \mathrm{~min}$. Following electrophoresis, slides were washed 3 times with water, once with $70 \%$ ethanol, and air dried. The dried slides were stained with $100 \mu \mathrm{L}$ of diluted Vista Green DNA dye (Cell Biolabs Inc., San Diego, CA), and cellular DNA was visualized using a FITC filter-fitted microscope. Comet images were scored visually on a scale of 0 to 4 as described by Collins [23], with 0 representing no damage and 4 representing severe damage.

\section{ELISA}

To generate ASC-conditioned media, we cultured fourth passage ASCs in complete media until confluence, and the old media was replaced with fresh. After 3 days, conditioned media were collected and centrifuged at $300 \mathrm{~g}$ for $5 \mathrm{~min}$. The resulting supernatants were frozen. The cells were also collected and the total number counted prior to protein extraction and quantification. IL-6, MCP-1, TNF-alpha, and IL-1 $\beta$ were measured using ELISAs purchased from R\&D Systems, Inc. (Minneapolis, MN).

\section{Western Blot Analysis}

Protein was isolated from ASCs at varying times using protein lysis buffer composed of $2 \mathrm{~mL} 5 \mathrm{X}$ lysate buffer $(750 \mathrm{mM}$ sodium chloride, $250 \mathrm{mM}$ Tris, $5 \%$ Triton X100, $5 \mathrm{mM}$ EDTA), 1 pill of protease inhibitor (Roche, Basel, Switzerland), $100 \mu \mathrm{L}$ of phosphatase inhibitor cocktail (Sigma, St. Louis, MO), and $66.7 \mu \mathrm{L}$ of phenylmethylsulfonyl fluoride in $8 \mathrm{~mL}$ of water. Total protein concentration was measured with the BCA protein assay as per manufacturer's instructions (Pierce, Rockford, IL). Following protein measurement, around $40 \mu \mathrm{g}$ of protein was quenched in buffer composed of $400 \mathrm{mM}$ Tris ( $\mathrm{pH}$ 6.8), $40 \%$ glycerol, $1 \%$ bromophenol blue, and $0.8 \mathrm{~mL}$ of $\beta$-mercaptoethanol in $10 \mathrm{~mL}$ of water. The samples were resolved on a sodium dodecyl sulfate polyacrylamide gel (Bio-Rad, Hercules, CA) at $150 \mathrm{~V}$ for $1 \mathrm{~h}$. The proteins were then transferred onto a PVDF membrane for $90 \mathrm{~min}$ at $400 \mathrm{~mA}$. Protein transfer to the 
membrane was confirmed by Ponceau staining. The membrane was incubated in $3 \%$ BSA for $1 \mathrm{~h}$ at the room temperature and incubated with a primary antibody to NF- $\mathrm{KB}$ (Abcam, Cambridge, MA; $1: 1000$ ) at $4{ }^{\circ} \mathrm{C}$ overnight. The blot was washed three times with Tris Buffered Saline s-Tween 20 for $10 \mathrm{~min}$ and incubated with HRP-conjugated anti-rabbit secondary antibody (1:5000) for $1 \mathrm{~h}$ at room temperature. The proteins were visualized using Enhanced chemiluminescence Fast Western blotting substrate (Thermo ScientificPierce, Rockford, IL) per the manufacturer's instructions. The membranes were then stripped and re-blotted with an anti-GAPDH rat antibody (Cell Signaling Technology, Danvers, MA; 1:1000) for $1 \mathrm{~h}$ at room temperature and HRP-conjugated anti-rabbit secondary antibody (Jackson ImmunoResearch Laboratories, Inc., West Grove, PA; 1:5000) for $1 \mathrm{~h}$ at room temperature. The intensity of band was measured using the Image J 1.47 software package (National Institutes of Health, imagej.nih.gov/ij/download/).

\section{Statistical Analysis}

Analysis of variance with Tukey's test and paired or unpaired Student's $t$ tests were used as appropriate. Data were expressed as the mean \pm standard error of the mean, as indicated. Significance was accepted at $p<0.05$.

\section{Results}

\section{The SVF and Adipocytes Produce Mediators of Inflammation Following Burn Injury}

Messenger RNA expression of inflammatory markers (IL-1 $\beta$, IL-6, MCP-1, caspase-1, TNF- $\alpha$, and NF-kB) was measured in freshly isolated adipocytes, the SVF, and enriched ASCs (Fig. 1). A significant elevation in IL-1 $\beta$ mRNA occurred in adipocytes and the SVF at 24 and $48 \mathrm{~h}$ following burn injury, compared to non-burned controls, $(p=0.037$, Fig. 1b). When compared to expression in non-burned controls, expression of IL-6 mRNA was significantly altered by burn injury ( $p=$ 0.009). In adipocytes, IL-6 mRNA increased while in ASCs it decreased, both at $48 \mathrm{~h}$ after injury ( $p=0.009$, Fig. $1 \mathrm{~b}$ ). A significant decrease in MCP-1 mRNA expression was found at 24 and $48 \mathrm{~h}$ postburn in enriched ASCs ( $p=0.005$, Fig. $1 \mathrm{c}$ ). TNF- $\alpha$ mRNA increased significantly in adipocytes at $48 \mathrm{~h}$ following burn injury ( $p=0.05$, Fig. $1 \mathrm{~d}$ ). Burn injury did not induce changes in expression of caspase-1 or NF- $\mathrm{kB}$ mRNA in any of the cell types, regardless of the time point (Fig. 1e, f). In ASCs, protein levels of IL-6, MCP-1, TNF- $\alpha$, IL- $1 \beta$, and NF-kB were unaffected by burn injury (data not shown).
DNA Damage Appears in the SVF Soon after Burn Injury but Resolves by 72 Hours Post Injury

DNA damage to the cells in the SVF and the enriched ASCs was assessed by comet assay. There was a significant induction of DNA damage in SVF isolated 24 and $48 \mathrm{~h}$ postburn ( $p=0.05, p=0.005$, respectively) (Fig. 2) compared to nonburned control. This amount of damage correlated to 4 damaged cells per 100 isolated cells. This damage resolved by $72 \mathrm{~h}$ postburn. In cultured ASCs, the level of damage remained the same throughout the 4-week experimental period. Burn injury and subsequent culturing of the ASCs did not induce DNA damage.

\section{Burn Injury Does Not Alter the Differentiation Potential of ASCs}

Following isolation and enrichment, ASCs were cultured in media formulated to induce differentiation into adipocytes, osteoblasts, chondrocytes, or epithelial cells. Differentiation into each of these cell types was confirmed by staining with oil O red (adipocytes), alizarin red (osteocytes), or alcian blue (chondrocytes) or by immunofluorescence staining for cytokeratin-14 (epithelial cells) (Fig. 3). ASCs from burn animals retained their differentiation capacity at all time points examined. The abundance of mRNA specific to each of the differentiated cell types was also measured. As shown in Fig. 4, we detected no significant differences between differentiated ASCs from non-burned and burned animals in levels of mRNA encoding factors involved in adipogenesis, (adipocyte lipid binding protein-1 and adiponectin [24]), chondrogenesis (chondromodulin 1 and collagen II $[25,26]$ ), osteogenesis (osteopontin and osteonectin [27]), and epithelial differentiation (cytokeratin [CK]-10 and CK-14).

\section{Postburn ASC Populations, as Identified by CD Marker Expression, Are Stable}

Expression of cell-surface and intracellular CD markers was assessed by flow cytometry. There were no significant differences in the expression of protein levels of CD11b, CD34, CD44, CD105, CD29, CD73, CD90, or CD36 (Fig. 5a, b). Similarly, there were no differences in the abundance of mRNA encoding these markers (data not shown).

\section{ASC Proliferation Is Not Affected by Burn Injury}

Measurement of cell proliferation over a 50-h period via cell impedance showed that cell proliferation was not altered by burn injury (Fig. 6). 

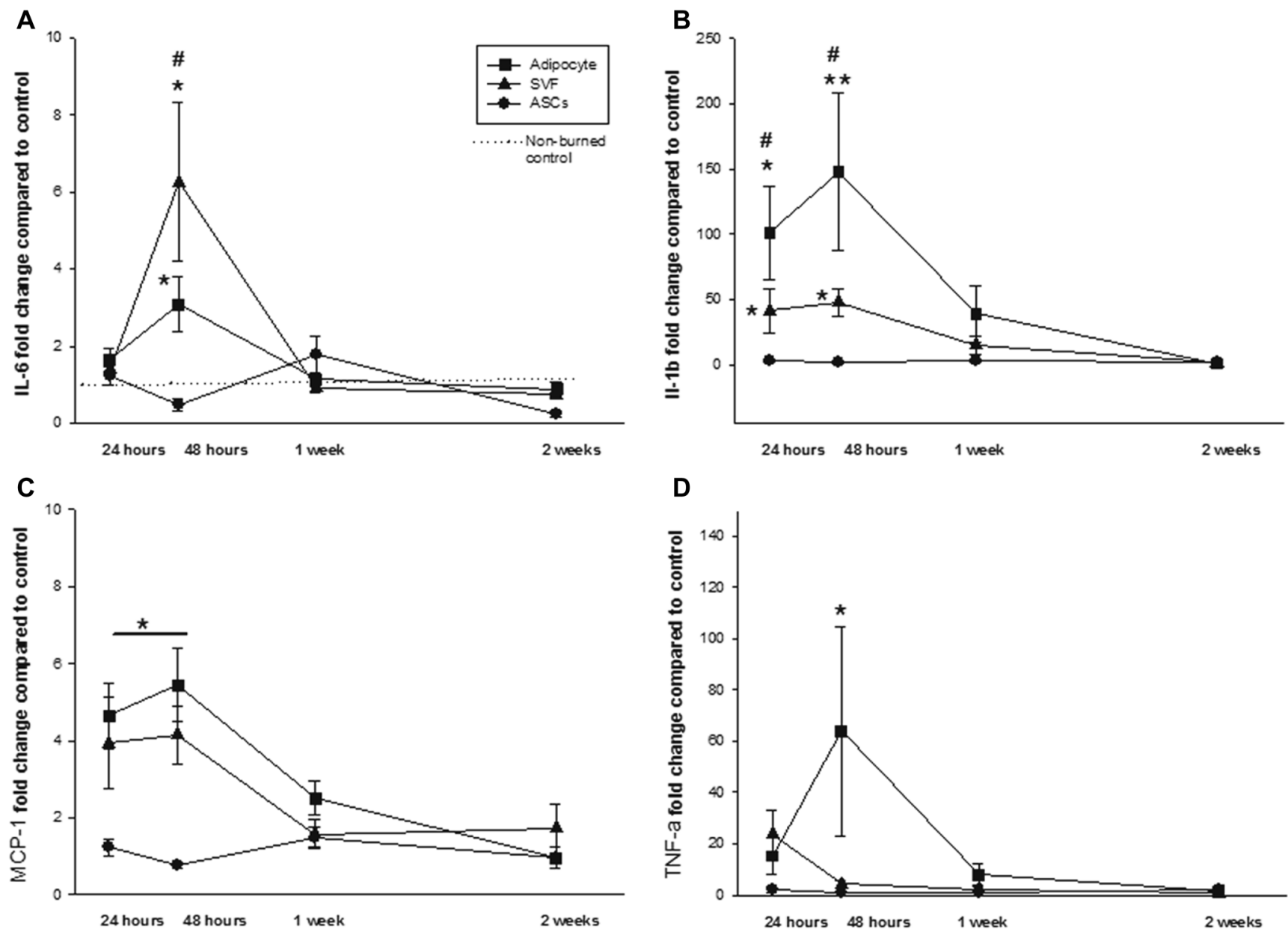

D
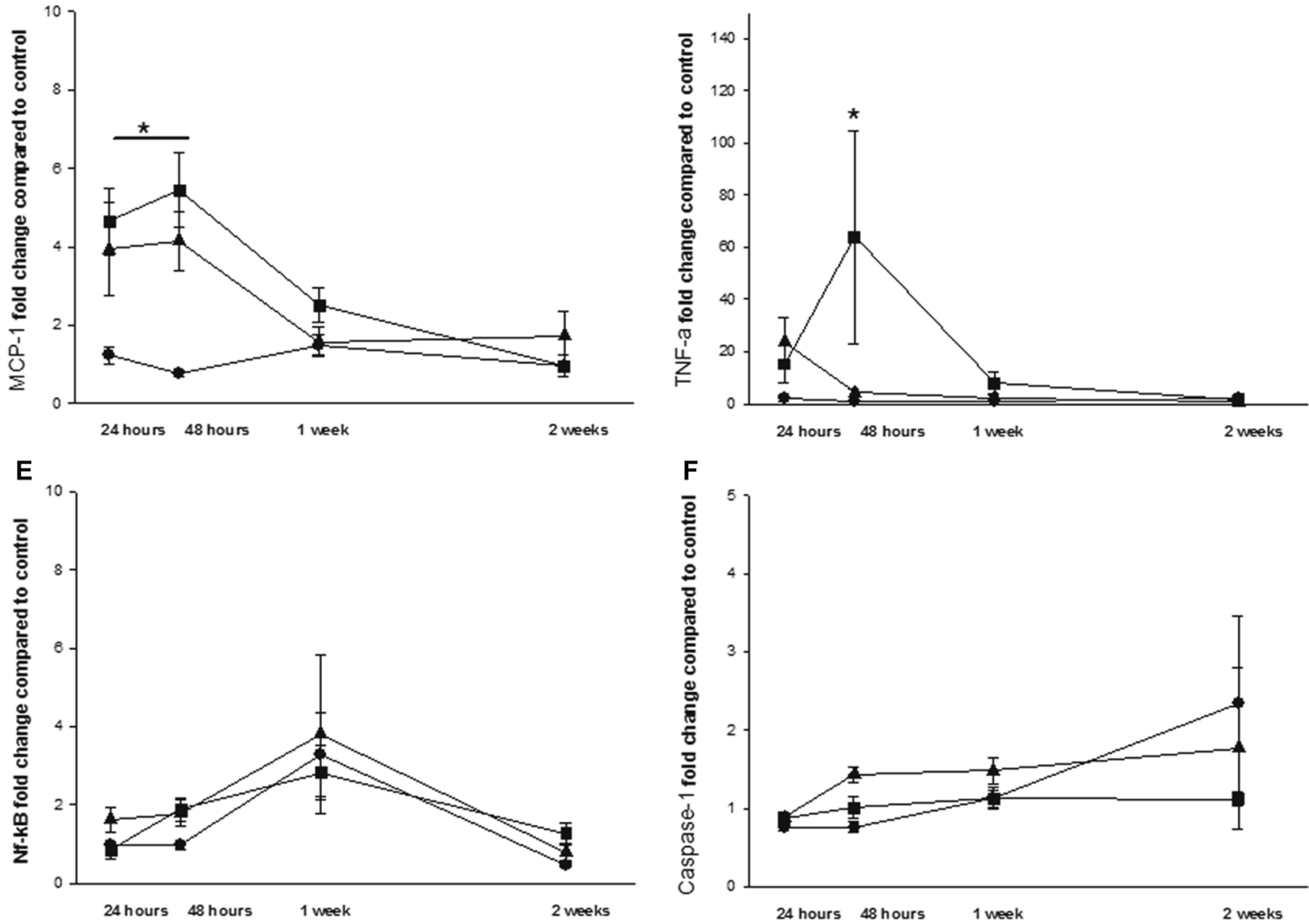

Fig. 1 Effect of burn injury on cytokine and transcription factor mRNA production by adipocytes, the stromal vascular fraction (SVF), and enriched ASCs. Temporal alterations in expression of (A) IL-6, (B) IL$1 \beta$, (C) MCP-1, (D) TNF- $\alpha$, (E) caspase-1, and (F) NF-kB are shown.

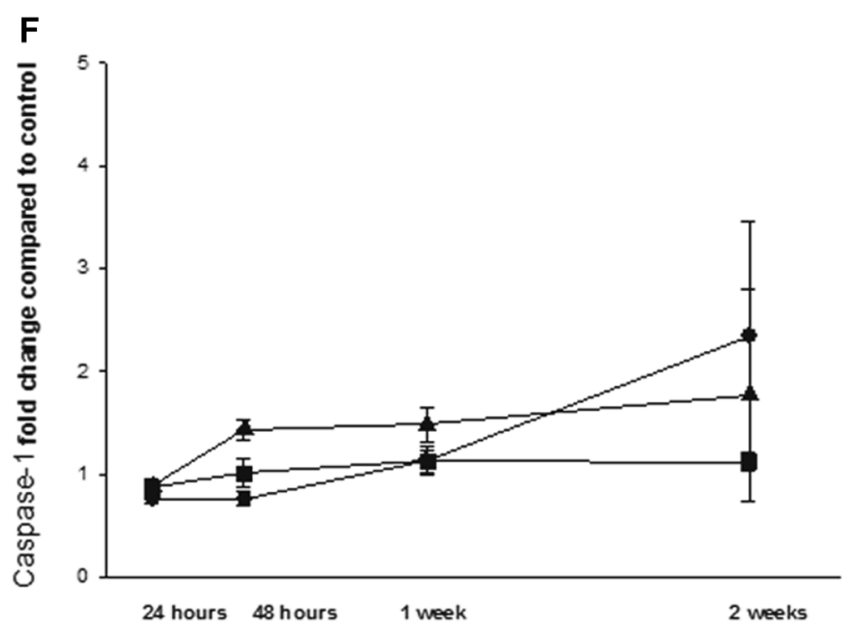

Data points represent mean \pm SEM of 8 control animals or 6 burned animals ( $24 \mathrm{~h}, 48 \mathrm{~h} 1$, and 2 weeks postburn \#p $<0.05$ vs. SVF, **p $<0.005$ vs. ASCs, $* \mathrm{p}<0.05$ vs. ASCs).

\section{Discussion}

Here we have shown that post-burn inflammation in the adipose tissue is mediated by the adipocytes and the SVF. Furthermore, we have shown that the effect of burn injury

on the ASCs is relatively small. ASCs can be isolated in great abundance, can differentiate into multiple cell types, and are believed to be safe for autologous and allogeneic transplantation [28]. Because of these qualities, ASC-based therapies have become one of the most promising approaches in the 
Fig. 2 Burn injury induces minimal DNA damage in the stromal vascular fraction (SVF) and enriched ASCs. Each bar represents the mean \pm SEM of 8 control animals or 6 burned animals $(24,48$, or $72 \mathrm{~h}, 1,2$, and 4 weeks postburn). $* p<0.05$ and $* * p<0.005$ vs. control

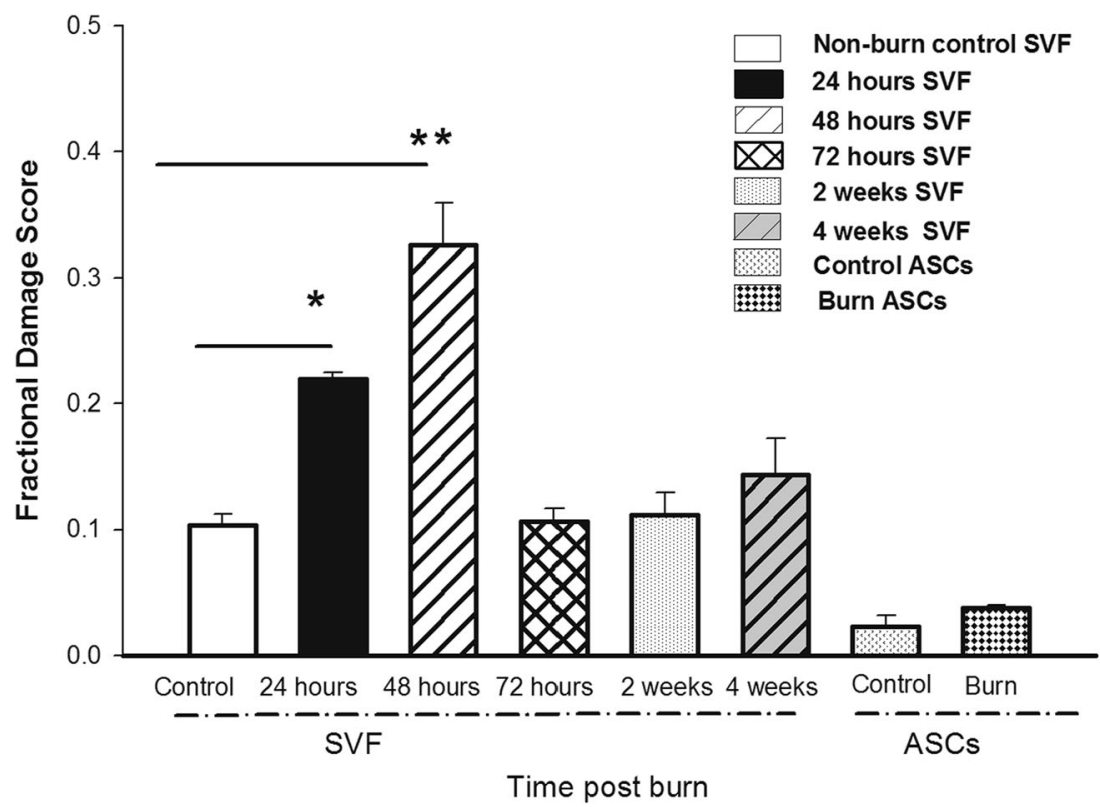

affect stem cells that may be utilized for therapeutic purposes is of paramount importance. Inflammation occurs in adipose tissue following injuries such as burns or in association with treatment of myriad diseases $[3,5,28]$. As it is possible to utilize a patient's own ASCs for repair and regeneration following injury or disease, characterization of how these insults

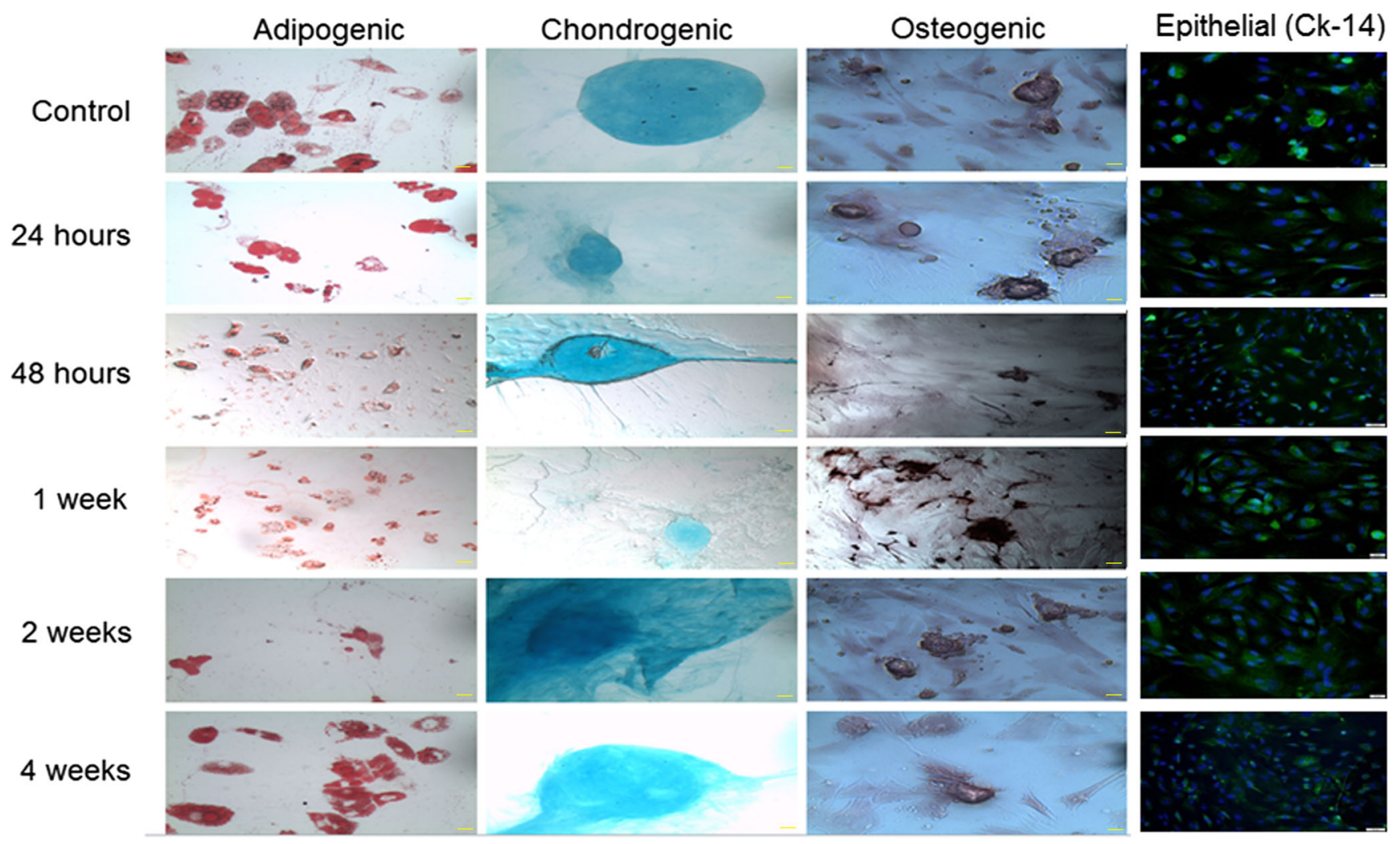

Fig. 3 Burn injury does not alter the ability of the ASCs to differentiate into adipogenic, chondrogenic, osteogenic, or epithelial lineages. Differentiated ASCs were identified by staining with oil-O-red (adipogenic cells), alcian blue (chondrogenic cells), or alizarin red (osteogenic cells) or by immunostaining for CK-14 (epithelial cells; green) and counterstaining nuclei with DAPI (blue). Images are shown at $10 \times$ magnification, with $50 \mu \mathrm{M}$ scale bar at the bottom right 

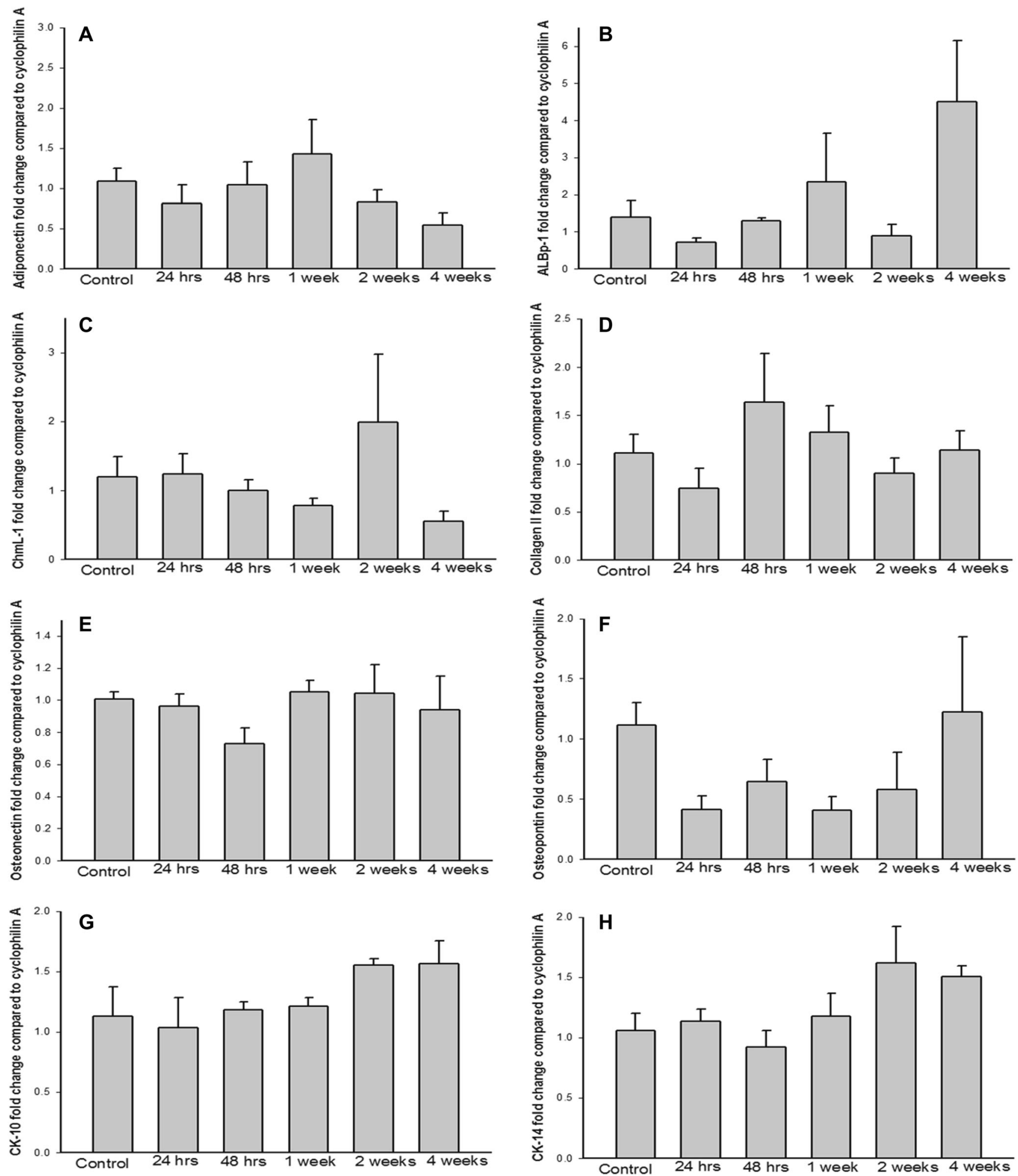

Fig. 4 Burn injury does not affect expression of cell type-specific genes in differentiated ASCs. Messenger RNA levels of (a) adiponectin and (b) adipocyte lipid binding protein 1 in adipogenic cells, (c) chondromodulin I and (d) collagen II in chondrogenic cells, (e) osteonectin and (f)

osteopontin in osteogenic cells, and (g) cytokeratin 10 and (h) cytokeratin 14 in epithelial cells. Each bar represents the mean \pm SEM of 8 control animals or 6 burned animals ( 24 and 48 h, 1, 2, and 4 weeks postburn)

diseases such as metabolic syndrome or diabetes. By altering that particular subpopulations of ASCs are selected to proceed toward a different fate or induced to migrate, thereby depleting 
Fig. 5 The ASC population is stable following burn injury, as confirmed by $\mathrm{CD}$ marker protein levels. No differences were detected in (a) CD29, CD73, CD90, or CD36 (b) or in CD11b, CD34, CD44, or CD105. Each bar represents the mean \pm SEM of 8 control animals or 6 burned animals ( $24 \mathrm{~h}, 1,2$, and 4 weeks postburn)
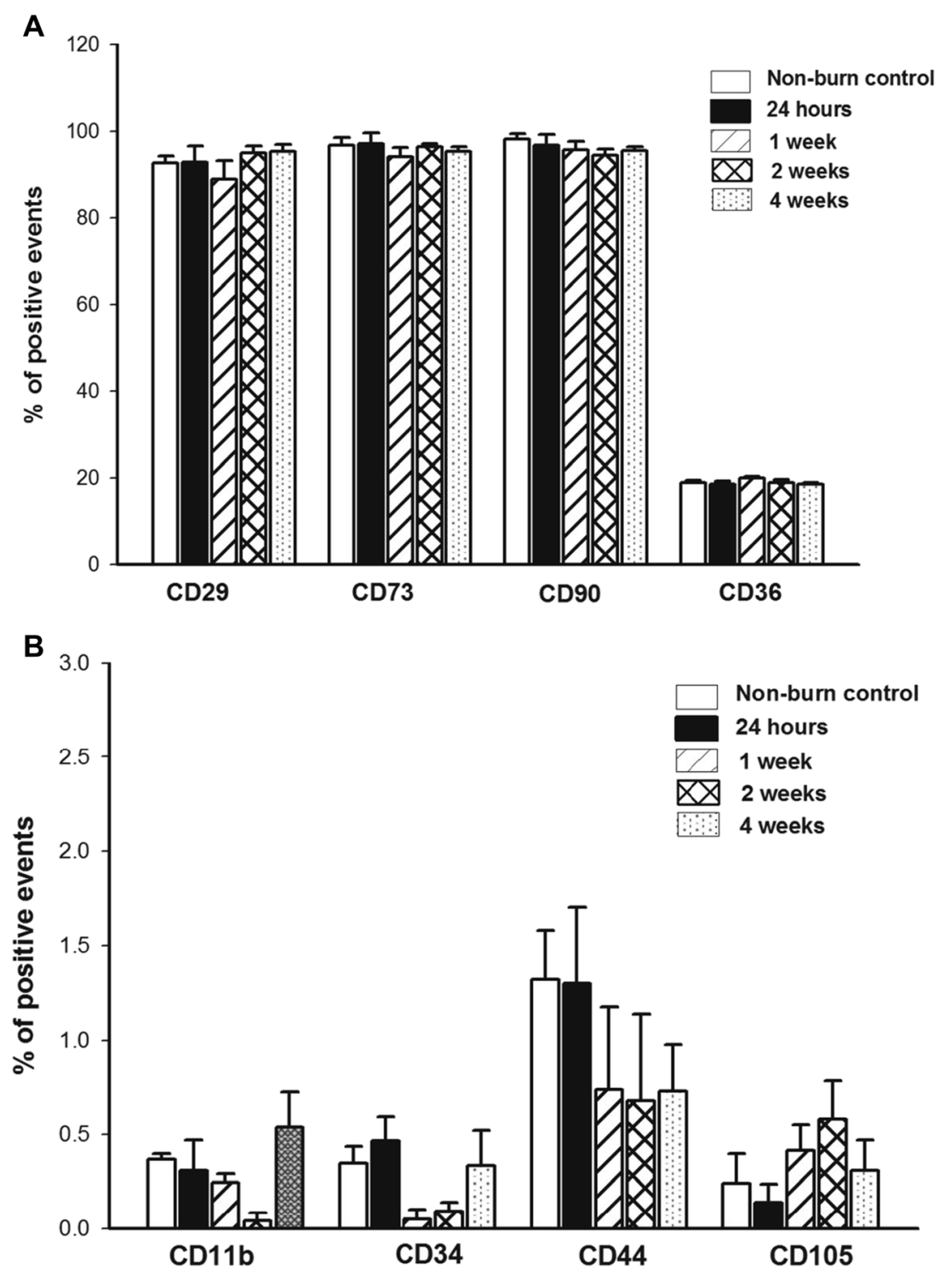

the tissue of specific subpopulations of ASCs and changing the overall ASC population that could be isolated for clinical use. Therefore, the purpose of our study was two-fold: 1) identify the cells within the adipose contributing mediators of inflammation to the response to burn injury and 2) determine the effect of burn injury on the fate and function of the ASCs. This was accomplished using the clinically relevant $60 \%$ rat scald burn model. Prior work has shown that this model induces a hypermetabolic response similar to that seen in patients with large burn injuries, including increased catabolism and inflammation [21]. Following isolation of the adipose tissue, we were able to obtain adipocytes and SVF for immediate study as well as enriched ASCs using a standard isolation protocol that yielded ASCs for study $48 \mathrm{~h}$ later. These studies show that inflammation comes from adipocytes and the SVF and that ASCs are not inflammatory in culture (nor are they affected by the burn injury and subsequent culturing procedures).

Stem cell fate and function are predominantly determined by dynamic interactions between the stem cells and their environment. Stem cells interact with the extracellular matrix, neighboring cells, and secreted proteins, allowing changes in the microenvironment to affect stem cells [18, 19, 29]. In adipose tissue, ASCs and adipocytes are surrounded by factors that facilitate tissue homeostasis under normal conditions. Following bury injury, many pro- and anti-inflammatory cytokines are elevated both systemically and locally within burned and non-burned tissue [20]. In freshly isolated adipocytes and SVF, we showed that IL- $1 \beta$ and IL- 6 are elevated in response to burn injury but that levels return to those seen under nonburn conditions between $48 \mathrm{~h}$ and 1 week following the 
Fig. 6 Burn injury does not affect proliferation of ASCs. Lines are averages of continuous measurements, and shaded regions around each line indicate SEM. Eight animals were included in the control group and 6 in the burned group $(24,48 \mathrm{~h}, 1$, 2 , and 4 weeks postburn)

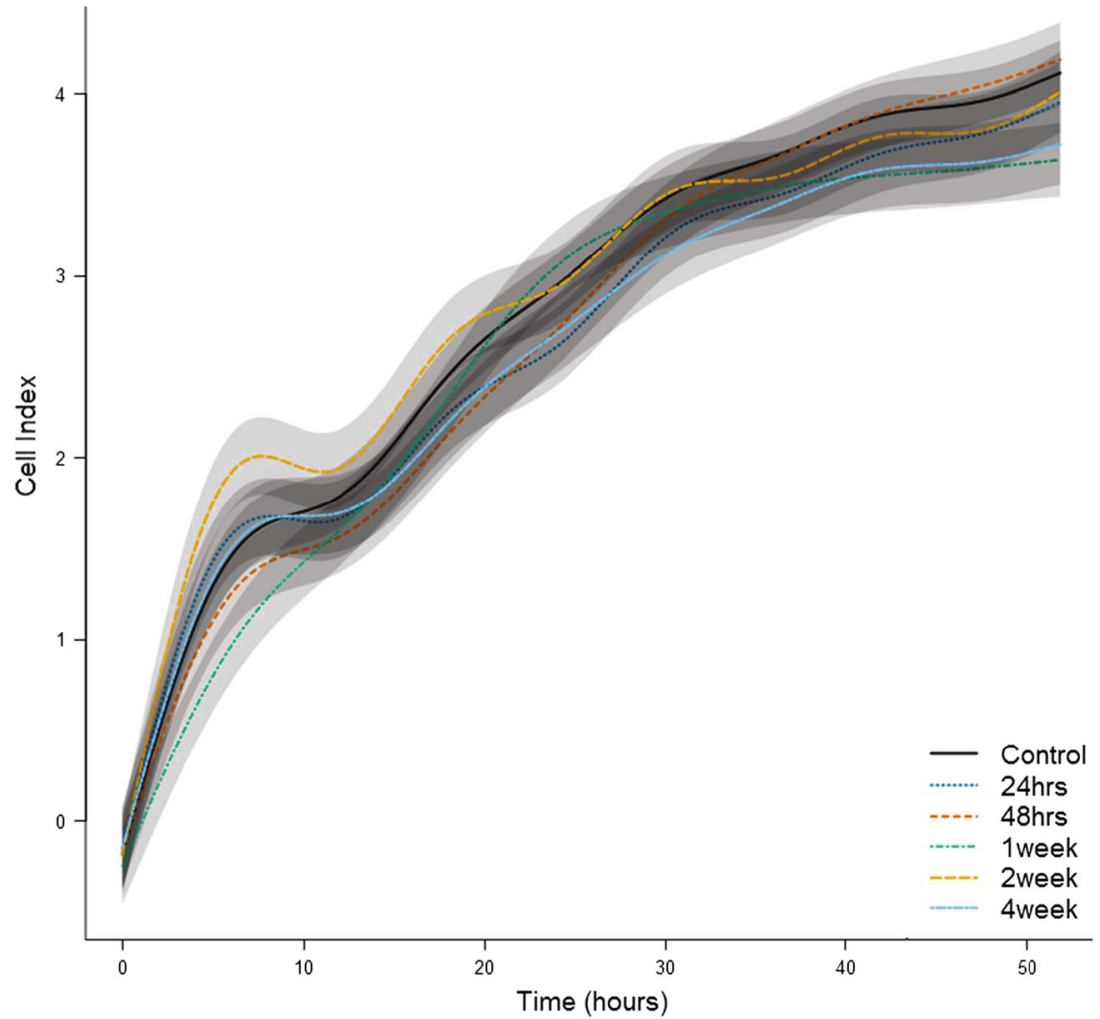

injury. Similarly, TNF- $\alpha$ was elevated in adipocytes but returned to normal levels after burn injury within the same temporal window. We are unable to measure immediate levels of inflammatory mediators in the ASCs, as the isolation protocol necessitates a 48-h incubation period. Therefore we measured the same markers in enriched, post-isolation ASCs that were cultured in vitro for $48 \mathrm{~h}$. Under these conditions, ASCs from burned animals produced similar levels of inflammatory markers as those from non-burned animals. An additional finding of interest was that the mature adipocytes produced significantly greater amounts of inflammatory markers than the SVF, which contains macrophages and other inflammatory cells. Within adipose tissue, ASCs, mature adipocytes, and other cell types likely function through paracrine signaling [30-32]. These interactions should be studied further to determine the role of this inflammatory response following burn injury. Additionally, we do not know whether increased DNA damage results in greater cell death within adipose tissue, leading to further increases in the local inflammatory response or whether this damage is repaired. The comet assay was performed to evaluate whether ASCs obtained following burn injury had increased DNA damage. Significantly higher fractional damage scores were recorded in the SVF isolated at 24 and $48 \mathrm{~h}$ postburn than in the non-burn control SVF. Whether these amounts of DNA damage are sufficient to affect tissue function or lead to aberrant cell behavior is unknown.

We were able to isolate ASCs from animals with large burn injuries. ASC identity was confirmed by measuring stemness markers; by differentiating the cells into osteogenic, chondrogenic, adipogenic, and epithelial cells [33]; and by verifying terminal differentiation into these cell types through measurement of cell type-specific gene expression. Burn injury did not change the ability of the ASCs to differentiate into other cell types. It also did not affect ASC proliferation or expression of mRNA for cytokines, growth factors, or CD markers related to burn injury.

Here we used the consensus definition to identify ASCs $[33,34]$. Most published studies have shown that CD13, CD90, CD73, CD29, CD36, and CD105 are positive markers for ASCs, while CD34 and CD11b/c are negative markers. Low expression of CD105 expression in rat ASCs could be mainly attributed due to lack of appropriate anti-rat CD105 antibody or an inadequate affinity of the CD105 antibody for the rat homologue as opposed to murine or human CD105. It may also be attributable to down regulation or loss of CD105 in culture [35].

In conclusion, ASCs obtained in a model of severe burn injury behave similarly to ASCs obtained from non-burned controls. Given the fact that inflammatory markers are elevated and DNA damage is increased 24 to $48 \mathrm{~h}$ postburn, we recommend that ASCs or SVF be used for tissue engineering 
or wound healing applications in severely burned patients after inflammation resolves. Confirmatory studies utilizing human tissue are needed to determine the timeline for resolution of the inflammation.

Acknowledgements The authors would like to thank Ye Wang and Hong-Jie Duan for their assistance during animal experiments. This work was supported by NIH (R01 GM112936, R01 GM056687, and P50 GM060338), Shriners of North America (80500), the Anderson Foundation, and the Gillson Longebaugh Foundation. The project was also conducted with the support of UTMB's Institute for Translational Sciences, supported in part by a Clinical and Translational Science Award (UL1 TR000071) from the National Center for Advancing Translational Sciences. AE was supported by a fellowship awarded by Shriners of North America (84202). None of the funding sources/sponsors had any involvement in the study design; in the collection, analysis, or interpretation of data; in the writing of the report; or in the decision to submit the article for publication.

\section{Compliance with Ethical Standards}

Research Involving Animals All animal experiments adhered to the guidelines detailed in the NIH Guide for the Care and Use of Laboratory Animals and were approved by the Institutional Animal Care and Use Committee at University of Texas Medical Branch (Galveston, TX).

Funding This study was funded by NIH (R01 GM112936, R01 GM056687, P50 GM060338, and UL1 TR000071), Shriners of North America (80500), and the Anderson Foundation and Gillson Longebaugh Foundation.

Conflict of Interest DNH received royalties from Elsevier and has received research grants from NIH, NIDILRR, DoD, Shriners of North America, the Anderson Foundation, and the Gillson Longebaugh Foundation. CCF has received research grants from NIH, DoD, Shriners of North America, and the Anderson Foundation.

Open Access This article is distributed under the terms of the Creative Commons Attribution 4.0 International License (http:// creativecommons.org/licenses/by/4.0/), which permits unrestricted use, distribution, and reproduction in any medium, provided you give appropriate credit to the original author(s) and the source, provide a link to the Creative Commons license, and indicate if changes were made.

\section{References}

1. Global Burden of Disease Study C. (2015). Global, regional, and national incidence, prevalence, and years lived with disability for 301 acute and chronic diseases and injuries in 188 countries, 19902013: a systematic analysis for the global burden of disease study 2013. Lancet, 386(9995), 743-800.

2. Adult stem cells. 2012. (Accessed September 21, 2016, at http:// stemcells.nih.gov/info/basics/).

3. Gimble, J. M., Katz, A. J., \& Bunnell, B. A. (2007). Adiposederived stem cells for regenerative medicine. Circulation Research, 100(9), 1249-60.

4. Lindroos, B., Suuronen, R., \& Miettinen, S. (2011). The potential of adipose stem cells in regenerative medicine. Stem Cell Reviews, $7(2), 269-91$.
5. Beeson, W., Woods, E., \& Agha, R. (2011). Tissue engineering, regenerative medicine, and rejuvenation in 2010: the role of adipose-derived stem cells. Facial Plastic Surgery, 27(4), 378-87.

6. Kilroy, G. E., Foster, S. J., Wu, X., Ruiz, J., Sherwood, S., Heifetz, A., et al. (2007). Cytokine profile of human adipose-derived stem cells: expression of angiogenic, hematopoietic, and proinflammatory factors. Journal of Cellular Physiology, 212(3), 702-9.

7. Wang, M., Crisostomo, P. R., Herring, C., Meldrum, K. K., \& Meldrum, D. R. (2006). Human progenitor cells from bone marrow or adipose tissue produce vegf, hgf, and igf-i in response to tnf by a p38 mapk-dependent mechanism. American Journal of Physiology. Regulatory, Integrative and Comparative Physiology, 291(4), R880-4.

8. Hu, D. H. (2010). expediting the study on the role of stem cells in wound treatment. Zhonghua Shao Shang Za Zhi, 26(4), 247-50.

9. Sorrell, J. M., \& Caplan, A. I. (2010). Topical delivery of mesenchymal stem cells and their function in wounds. Stem Cell Research \& Therapy, 1(4), 30.

10. Lequeux, C., Oni, G., Wong, C., Damour, O., Rohrich, R., Mojallal, A., et al. (2012). Subcutaneous fat tissue engineering using autologous adipose-derived stem cells seeded onto a collagen scaffold. Plastic and Reconstructive Surgery, 130(6), 1208-17.

11. Zografou, A., Papadopoulos, O., Tsigris, C., Kavantzas, N., Michalopoulos, E., Chatzistamatiou, T., et al. (2013). Autologous transplantation of adipose-derived stem cells enhances skin graft survival and wound healing in diabetic rats. Annals of Plastic Surgery, 71(2), 225-32.

12. Wurzer P., Guillory A., Parvizi D., Clayton R.P., Branski L.K., Kamolz L.P., et al. (2016). Human herpes viruses in burn patients: A systematic review. Burns, 43(1), 25-33.

13. Chan R.K., Zamora D.O., Wrice N.L., Baer D.G., Renz E.M., Christy R.J., et al. (2012). Development of a vascularized skin construct using adipose-derived stem cells from debrided burned skin. Stem Cells Int, 2012(841203.

14. Arno, A., Smith, A., Blit, P., Al, S. M., Gauglitz, G. G., \& Jeschke, M. G. (2011). Stem cell therapy: a new treatment for burns? Pharmaceuticals, 4(10), 1355-80.

15. Finnerty, C. C., Przkora, R., Herndon, D. N., \& Jeschke, M. G. (2009). Cytokine expression profile over time in burned mice. Cytokine, 45(1), 20-5.

16. Finnerty, C. C., Jeschke, M. G., Herndon, D. N., Gamelli, R., Gibran, N., Klein, M., et al. (2008). Temporal cytokine profiles in severely burned patients: a comparison of adults and children. Molecular Medicine, 14(9-10), 553-60.

17. Liu, Y., Li, Z., Liu, T., Xue, X., Jiang, H., Huang, J., et al. (2013). Impaired cardioprotective function of transplantation of mesenchymal stem cells from patients with diabetes mellitus to rats with experimentally induced myocardial infarction. Cardiovascular Diabetology, 12, 40.

18. Li, L. H., \& Xie, T. (2005). Stem cell niche: structure and function. Annual Review of Cell and Developmental Biology, 21, 605-31.

19. Spradling, A., Drummond-Barbosa, D., \& Kai, T. (2001). Stem cells find their niche. Nature, 414(6859), 98-104.

20. Jeschke, M. G., Finnerty, C. C., Herndon, D. N., Song, J., Boehning, D., Tompkins, R. G., et al. (2012). Severe injury is associated with insulin resistance, endoplasmic reticulum stress response, and unfolded protein response. Annals of Surgery, 255(2), 370-8.

21. Herndon, D. N., Wilmore, D. W., \& Mason, A. D., Jr. (1978). Development and analysis of a small animal model simulating the human postburn hypermetabolic response. Journal of Surgical Research, 25(5), 394-403.

22. Mascarenhas, D. D., Elayadi, A., Singh, B. K., Prasai, A., Hegde, S. D., Herndon, D. N., et al. (2013). Nephrilin peptide modulates a neuroimmune stress response in rodent models of burn trauma and sepsis. International Journal of Burns and Trauma, 3(4), 190-200. 
23. Collins, A. R. (2004). The comet assay for DNA damage and repair: principles, applications, and limitations. Molecular Biotechnology, 26(3), 249-61.

24. Dani, C., Doglio, A., Amri, E. Z., Bardon, S., Fort, P., Bertrand, B., et al. (1989). Cloning and regulation of a mrna specifically expressed in the preadipose state. Journal of Biological Chemistry, 264(17), 10119-25.

25. Klinger, P., Surmann-Schmitt, C., Brem, M., Swoboda, B., Distler, J. H., Carl, H. D., et al. (2011). Chondromodulin 1 stabilizes the chondrocyte phenotype and inhibits endochondral ossification of porcine cartilage repair tissue. Arthritis and Rheumatism, 63(9), 2721-31.

26. Tarpey, P. S., Behjati, S., Cooke, S. L., Van Loo, P., Wedge, D. C., Pillay, N., et al. (2013). Frequent mutation of the major cartilage collagen gene col2a1 in chondrosarcoma. Nature Genetics, 45(8), 923-6.

27. Aarden, E. M., Wassenaar, A. M., Alblas, M. J., \& Nijweide, P. J. (1996). Immunocytochemical demonstration of extracellular matrix proteins in isolated osteocytes. Histochemistry and Cell Biology, 106(5), 495-501.

28. Gimble, J. M., \& Nuttall, M. E. (2011). Adipose-derived stromal/ stem cells (ASC) in regenerative medicine: pharmaceutical applications. Current Pharmaceutical Design, 17(4), 332-9.

29. Kaewsuwan, S., Song, S. Y., Kim, J. H., \& Sung, J. H. (2012). Mimicking the functional niche of adipose-derived stem cells for regenerative medicine. Expert Opinion on Biological Therapy, 12(12), 1575-88.
30. Eming, S. A., Krieg, T., \& Davidson, J. M. (2007). Inflammation in wound repair: molecular and cellular mechanisms. Journal of Investigative Dermatology, 127(3), 514-25.

31. Pallares, V., Castell-Auvi, A., Cedo, L., Pinent, M., Ardevol, A., \& Blay, M. (2010). A paracrine loop between adipocytes and macrophages in adipose tissue: an in vitro model to study obesity-induced inflammation. Journal of Nutrigenetics and Nutrigenomics, 3(2-3), 96.

32. Suganami, T., Nishida, J., \& Ogawa, Y. (2005). A paracrine loop between adipocytes and macrophages aggravates inflammatory changes - role of free fatty acids and tumor necrosis factor alpha. Arteriosclerosis, Thrombosis, and Vascular Biology, 25(10), 2062-68.

33. Bourin, P., Bunnell, B. A., Casteilla, L., Dominici, M., Katz, A. J., March, K. L., et al. (2013). Stromal cells from the adipose tissuederived stromal vascular fraction and culture expanded adipose tissue-derived stromal/stem cells: a joint statement of the International Federation for Adipose Therapeutics and Science (IFATS) and the International Society for Cellular Therapy (ISCT). Cytotherapy, 15(6), 641-8.

34. Dominici, M., Le Blanc, K., Mueller, I., Slaper-Cortenbach, I., Marini, F., Krause, D., et al. (2006). Minimal criteria for defining multipotent mesenchymal stromal cells. The international society for cellular therapy position statement. Cytotherapy, 8(4), 315-7.

35. Anderson, P., Carrillo-Galvez, A. B., Garcia-Perez, A., Cobo, M., \& Martin, F. (2013). Cd105 (endoglin)-negative murine mesenchymal stromal cells define a new multipotent subpopulation with distinct differentiation and immunomodulatory capacities. PloS One, 8(10), e76979. 